\title{
Optimization Research of Batch Order Processing Queue in Internet Consumption Custom Marketing
}

\author{
Rui Wang ${ }^{1, a}$, Jiao Tang ${ }^{2, b^{*}}$ and Ye Yang ${ }^{3, c}$ \\ ${ }^{1,2,3}$ School of Business, Sichuan University, Chengdu, China \\ athumb1920@163.com, 'b62208034@qq.com, 624213188@qq.com
}

\begin{abstract}
Keywords: Bach orders; processing queue; project management; extension AHP; multilevel grey comprehensive evaluation
\end{abstract}

\begin{abstract}
In recent years, with the rapid development of e- commerce, internet consumption custom is increasingly favored by consumers. So how to handle a variety of orders effectively and orderly is the main problem in this article. We could convert batch order processing to priority evaluation of order project by using the idea of project management. Firstly, we establish order evaluation system to confirm order processing queue, and the extension AHP method is used to find the weight. Then, the modeling of multilevel grey comprehensive evaluation is available to determine order project priority. Finally, we illustrate the optimization method is feasible through numerical examples.
\end{abstract}

\section{Introduction}

Recently, e-commerce has made rapid development in China. As a result, a growing number of consumers want to find the commodity which would reflect their unique personality. With the increasing demand and the wide application of big data analysis, small and medium-sized enterprises began to implement the internet consumption custom marketing. Before the 1980s, customized marketing is just a forward-looking vision. Until 1993, B. Joseph Pine II gave a complete description of mass customization ${ }^{[1]}$. After that, the topic of mass customization has been abstracted, related research on the one hand, including the concept, classification, the significance and so on ${ }^{[2-4]}$. On the other hand, there are many literatures on customization marketing strategy under the background of Internet ${ }^{[5-7]}$.

We note that the above articles directly determine the order priority. It is not only time-consuming but also affects the production and distribution. By contrast, we assume that the commodities are non-seasonal, and customer number is relatively large, so the mass orders are varieties. We can integrate orders in the same province into programs, and design order processing queue from a strategic perspective. This will be conducive to improve customer satisfaction with goods.

The paper is organized as follows. In Section 2, we propose order processing queue after the integration of the order project. And then adopt extension AHP method to find weights. In Section 3, we develop a multilevel grey comprehensive evaluation model as the optimization of order processing queue. Specific numerical examples are described in section 4. In section 5 we summarize the method and present suggestions for future research.

\section{Order processing queue}

\subsection{Identifying evaluation index}

According to the features of internet consumption custom products, we impose the following indicators: the financial index Y1 embraces total investment Y11 and average profit Y12; Strategic index Y2 comprises city attention Y21 and enterprise reputationY22; Core competitiveness index Y3 is reflected in employee satisfaction Y31, staff study ability Y32 and staff innovation Y33; Development of business coordination Y41 and promotion of technology level Y42 are drawn in enterprise internal operating index Y4; The last one is customers influence index Y5.

\subsection{Determining the index weight}

Under a certain criterion, experts compare the relative importance of each index in the same level, and establish extension interval judgment matrix $A=\left(a_{i j}\right)_{n \times n} i, j=1 \ldots n$ as positive reciprocal matrix, 
where $a_{i j}=\left(a_{i j}^{-}, a_{i j}^{+}\right)$is called extension interval and $a_{i j}^{+}, a_{i j}^{-}$are bipolar endpoints of extension interval elements. $\frac{1}{2}\left(a_{i j}^{-}+a_{i j}^{+}\right)$is 1-9 scale number that are used to compare in AHP. As shown in table 1:

Table 1 Importance level scoring

\begin{tabular}{|c|c|c|}
\hline Scale & Importance level & Score \\
\hline 1 & i and $\mathrm{j}$ are the same importance & 1 \\
\hline 2 & $\mathrm{i}$ than $\mathrm{j}$ is somewhat importance & 3 \\
\hline 3 & $\mathrm{i}$ than $\mathrm{j}$ is obviously importance & 5 \\
\hline 4 & $\mathrm{i}$ and $\mathrm{j}$ are strongly importance & 7 \\
\hline 5 & $\mathrm{i}$ and $\mathrm{j}$ are extremely importance & 9 \\
\hline 6 & $\mathrm{i}$ and $\mathrm{j}$ are not somewhat importance & $1 / 3$ \\
\hline 7 & $\mathrm{i}$ and $\mathrm{j}$ are not obviously importance & $1 / 5$ \\
\hline 8 & $\mathrm{i}$ and $\mathrm{j}$ are not strongly importance & $1 / 7$ \\
\hline 9 & $\mathrm{i}$ and $\mathrm{j}$ are not extremely importance & $1 / 9$ \\
\hline
\end{tabular}

Next, according to scores of experts, the weight vector can be obtained. If $A=\left(A^{-}, A^{+}\right)$, where $A^{-}$denote the lower end in the extension interval matrix, in contrast, $A^{+}$denote the upper end one, then the result will be $a_{i j}=\frac{1}{N}\left(a_{i j}^{1}+a_{i j}^{2}+\ldots . a_{i j}^{N}\right)$ in the case of $N$ experts. Receiving the weight vector in the consistent condition can follow below steps:

1) Computing feature vectors: The largest eigenvalue of $A^{-}, A^{+}$corresponding to the normalized feature vectors $x^{-}, x^{+}$which have a positive component.

2) Calculating $k$ and $m$ :

$$
\begin{aligned}
& k=\sqrt{\sum_{j=1}^{n}\left(\frac{1}{\sum_{i=1}^{n} a^{+}}\right)} \\
& m=\sqrt{\sum_{j=1}^{n}\left(\frac{1}{\sum_{i=1}^{n} a_{i j}^{-}}\right)}
\end{aligned}
$$

3)Judging the consistency of matrix: If $0 \leq k \leq 1 \leq m$, it shows that the consistency of extension interval judgment matrix is good. Otherwise, it needs to regain the judgement matrix until it passes the inspection.

4)Counting the weight vector:

$$
S=\left(S_{1}, S_{2}, \ldots . S_{n_{k}}\right)=\left(k x^{-}, m x^{+}\right)
$$

5)Ranking: First, single order. If there exits $i, j$, and $i \neq j$ making $V\left(S_{i} \geq S_{j}\right) \geq 0$, so $p_{j}=1$.

$$
p_{i}=V\left(S_{i} \geq S_{j}\right)=\frac{2 \times\left(S_{i}^{+}-S_{j}^{-}\right)}{\left(S^{+}{ }_{j}-S_{j}^{-}\right)+\left(S^{+}{ }_{i}-S^{-}{ }_{i}\right)}
$$

with $i, j=1,2 \ldots n$ and $i \neq j$. So $p=\left(p_{1}, p_{2}, \ldots p_{n}\right)$ represents a single sequence which each element in a certain level associates with some element in the upper one.

Then, the level of total order, according to the hierarchical structure, can be obtained from the top to the bottom. Calculating $n_{k} \times n_{k-1}$ matrix when $p_{h}^{k}=\left(p_{1 h}^{k}, p_{2 h}^{k}, \ldots, p_{n_{k}}^{k}\right)^{T}, h=1,2 \ldots n_{k-1}$, in which $k$ is the layer level $k$ and $h$ is the element $h$. If the weight vector belonging to the whole goal is $w^{k-1}=\left(w_{1}^{k-1}, w_{2}^{k-1}, \ldots . w_{n_{k-1}}^{k-1}\right)^{T}$ in the $k-1$ layer, $w^{k}=p^{k} w^{k-1}$ is the value in $k$ layer. Further, the weight of each index can be found.

\section{Optimizing order processing queue}

In the consumption custom marketing, enterprises are familiar with orders, order type and geographic location, but they do not know or know little whether customers will improve enterprise 
reputation and enhance the enterprise core competitive ability or not. The condition suits the grey system $^{[8]}$, so we choose a multi-level grey comprehensive evaluation method ${ }^{[9]}$.

\subsection{Creating the scoring matrix}

We assume that there is $j$ related to person giving $i$ order items scores according to a score level. Finally, we obtain scoring matrixes about evaluation index $k$.

$$
D^{k}=\left(\begin{array}{ccc}
d^{k}{ }_{11} & \ldots & d^{k}{ }_{1 j} \\
\vdots & \ddots & \vdots \\
d^{k}{ }_{i 1} & \cdots & d^{k}{ }_{i j}
\end{array}\right)
$$

\subsection{Determining the evaluation of grey type}

To determine grey type evaluation, we need to determine rank number, grey number and definite weighted function. In this paper, we adopt three types: high, middle and low level. That is:

High level: Grey type is $\otimes 1 \in[8, \infty]$, and whiten function $f_{1}$ is

$$
f_{1}=\left\{\begin{array}{cc}
d_{i j}^{k} / 8 & d_{i j}^{k} \in[0,8) \\
1 & d_{i j}^{k} \in[8, \infty)
\end{array}\right.
$$

Middle level: Grey type is $\otimes 2 \in[0,5,10]$, and whiten function $f_{2}$ is

$$
f_{2}=\left\{\begin{array}{cc}
d_{i j}^{k} / 5 & d_{i j}^{k} \in[0,5) \\
1 & d_{i j}^{k}=10 \\
\left(10-d_{i j}^{k}\right) / 5 & d_{i j}^{k} \in(5,10]
\end{array}\right.
$$

Low level: Grey type is $\otimes 3 \in[0,1,4]$, and whiten function $f_{3}$ is

$$
f_{3}=\left\{\begin{array}{cc}
1 & d_{i j}^{k} \in[0,1) \\
\left(4-d_{i j}^{k}\right) / 3 & d_{i j}^{k} \in(1,4]
\end{array}\right.
$$

\subsection{Counting the grey evaluation coefficient}

The evaluation coefficients of order project $i$ are all reviewers giving about evaluation index $k$.

$$
n_{i h}^{k}=\sum_{j=1}^{n} f_{h}\left(d_{i j}^{k}\right) \quad i=1 . . m, k=1,2, . . \mathrm{K}, h=1,2,3
$$

Total evaluation coefficient:

$$
n_{i}^{k}=\sum_{h=1}^{3} \sum_{j=1}^{n} f_{h}\left(d_{i j}^{k}\right) \quad i=1 . . m, k=1,2, . . \mathrm{K}
$$

Therefore, we can get grey evaluation weight vector of order project $i$ relating to evaluation index $k$.

$$
r_{i}^{k}=\left(r_{i 1}^{k}, r_{i 2}^{k} \ldots . r_{i h}^{k}\right)=\left(n_{i 1}^{k} / n_{i}^{k}, n_{i 2}^{k} / n_{i}^{k} \ldots . n_{i h}^{k} / n_{i}^{k}\right)
$$

All grey evaluation weight vectors could form assessment weight matrixes.

\subsection{Comprehensive assessment}

$$
R^{k}=\left(\begin{array}{ccc}
r_{11}^{k} & \cdots & r_{1 h}^{k} \\
\vdots & \ddots & \vdots \\
r_{m h}^{k} & \cdots & r_{m h}^{k}
\end{array}\right)
$$

The maximum grey evaluation weight can be obtained by $R^{k}$.

$$
r_{i}^{*(k)}=\max \left(r_{i h}^{k}\right) \quad h=1,2,3
$$

In the same way, All the evaluation weights for evaluation index $k$ follow it:

$$
r^{*(k)}=\left(\begin{array}{lll}
r_{1}^{*(k)} & r_{2}^{*(k)} \ldots . r_{m}^{*(k)}
\end{array}\right)
$$

So, evaluation weight matrixes are:

$$
r^{*}=\left(r^{*(1)} r^{*(2)} \ldots . r^{*(K)}\right)^{T}
$$


Then, we calculate the comprehensive score $w r^{*}$ to determine the priority of the order project.

\section{Numerical examples}

Assuming that a company receives five project orders during the planning period, the company needs to optimize the order processing queue to allocate resources reasonably. The above method and model are applied to sort order project priority.

\subsection{Identifying the index weight}

There are two experts giving scores for evaluation index, as shown in Table 2 and Table 3. By calculating the weight of $Y 1, Y 2, Y 3, Y 4, Y 5$ as example, the solving steps are followings.

Table 2 Score of the relative importance by one expert

\begin{tabular}{|l|l|l|l|l|l|}
\hline & $\begin{array}{l}\text { Financial } \\
\text { index }\end{array}$ & $\begin{array}{l}\text { strategic } \\
\text { index }\end{array}$ & $\begin{array}{l}\text { core } \\
\text { competitiveness } \\
\text { index }\end{array}$ & $\begin{array}{l}\text { Internal } \\
\text { operating index }\end{array}$ & $\begin{array}{l}\text { Customers } \\
\text { influence index }\end{array}$ \\
\hline Financial index & $(1.00,1.00)$ & $(4.50,5.50)$ & $(2.50,3.50)$ & $(2.50,3.50)$ & $(1.00,1.00)$ \\
\hline strategic index & $(0.18,0.22)$ & $(1.00,1.00)$ & $(1.00,1.00)$ & $(3.50,4.50)$ & $(0.29,0.40)$ \\
\hline $\begin{array}{l}\text { core competitiveness } \\
\text { index }\end{array}$ & $(0.29,0.40)$ & $(1.00,1.00)$ & $(1.00,1.00)$ & $(3.50,4.50)$ & $(0.37,0.75)$ \\
\hline Internal operating index & $(0.29,0.40)$ & $(0.18,0.22)$ & $(0.18,0.22)$ & $(1.00,1.00)$ & $(0.27,0.43)$ \\
\hline $\begin{array}{l}\text { Customers influence } \\
\text { index }\end{array}$ & $(1.00,1.00)$ & $(2.50,3.50)$ & $(1.33,2.67)$ & $(2.33,3.70)$ & $(1.00,1.00)$ \\
\hline
\end{tabular}

Table 3 Score of the relative importance by another expert

\begin{tabular}{|l|l|l|l|l|l|}
\hline & $\begin{array}{l}\text { Financial } \\
\text { index }\end{array}$ & $\begin{array}{l}\text { strategic } \\
\text { index }\end{array}$ & $\begin{array}{l}\text { core } \\
\text { competitiveness } \\
\text { index }\end{array}$ & $\begin{array}{l}\text { Internal } \\
\text { operating index }\end{array}$ & $\begin{array}{l}\text { Customers } \\
\text { influence } \\
\text { index }\end{array}$ \\
\hline Financial index & $(1.00,1.00)$ & $(4.50,5.50)$ & $(3.50,4.50)$ & $(3.50,4.50)$ & $(2.50,3.50)$ \\
\hline strategic index & $(0.18,0.22)$ & $(1.00,1.00)$ & $(2.50,3.50)$ & $(1.50,2.50)$ & $(1.50,2.50)$ \\
\hline core competitiveness index & $(0.22,0.29)$ & $(0.29,0.40)$ & $(1.00,1.00)$ & $(3.50,4.50)$ & $(0.38,0.71)$ \\
\hline Internal operating index & $(0.22,0.29)$ & $(0.40,0.67)$ & $(0.22,0.29)$ & $(1.00,1.00)$ & $(0.20,0.33)$ \\
\hline Customers influence index & $(0.29,0.40)$ & $(0.40,0.67)$ & $(1.40,2.6)$ & $(3.00,5.00)$ & $(1.00,1.00)$ \\
\hline
\end{tabular}

Combined with evaluation model, we can have normalized feature vectors

$$
x^{-}=\left(\begin{array}{lllll}
0.43 & 0.16 & 0.13 & 0.06 & 0.22
\end{array}\right), x^{+}=\left(\begin{array}{lllll}
0.41 & 0.17 & 0.13 & 0.06 & 0.23
\end{array}\right) \text {. }
$$

Then from Eq. 1 and 2, it follows that $k=0.9043, m=1.0010,0 \leq \mathrm{k} \leq 1 \leq \mathrm{m}$, so the consistency of judgment matrix is good. By Eq. 3 and 4 , we have $P 1=25.99, P 2=7.41, P 3=8.28, P 4=1, P 5=9.48$.

After the normalization of vectors, we can get $P=(0.49830 .14210 .15870 .01920 .1817)$,namely, the weights are $Y 1=0.4983, Y 2=0.1421, Y 3=0.1587, Y 4=0.0192, Y 5=0.1817$. Similarly to calculate the weight of each evaluation index, $Y 11=0.4877, Y 12=0.5123, Y 21=0.7068, Y 22=0.2932, Y 31=0.0103$, $Y 32=0.5614, \mathrm{Y} 33=0.4283, \mathrm{Y} 41=0.8341, \mathrm{Y} 42=0.1659$.

\subsection{Building the scoring matrix}

Now enterprise has invited 4 relative persons to grade 9 evaluation indexes, the score of which ranges from one to ten points. We can acquire specific matrixes through Eq.5.

$$
D^{1}=\left[\begin{array}{l}
8798 \\
9878 \\
8676 \\
7678 \\
6757
\end{array}\right] \quad D^{2}=\left[\begin{array}{l}
7598 \\
7765 \\
8666 \\
4586 \\
6538
\end{array}\right] \quad D^{3}=\left[\begin{array}{l}
6584 \\
7526 \\
8564 \\
7573 \\
6548
\end{array}\right] \quad D^{4}=\left[\begin{array}{l}
2487 \\
4273 \\
7564 \\
4739 \\
6258
\end{array}\right] \quad D^{5}=\left[\begin{array}{l}
5924 \\
6843 \\
7538 \\
4737 \\
9462
\end{array}\right] \quad D^{6}=\left[\begin{array}{l}
4627 \\
7433 \\
4856 \\
8524 \\
6546
\end{array}\right] \quad D^{7}=\left[\begin{array}{l}
5386 \\
7358 \\
8562 \\
4937 \\
8746
\end{array}\right] \quad D^{8}=\left[\begin{array}{l}
5474 \\
4826 \\
7548 \\
7652 \\
5863
\end{array}\right] \quad D^{9}=\left[\begin{array}{l}
7425 \\
5836 \\
3597 \\
4648 \\
7526
\end{array}\right]
$$

\subsection{Calculating grey evaluation coefficients}

We take evaluation coefficient of the order project 1 for an example. Then from Eq.6 to 9, it follows that: 


$$
\text { when } h=1, n_{11}^{1}=3.875 \text {, when } h=2, n_{12}^{1}=1.6 \text {, when } h=3, n_{13}^{1}=0
$$

Therefore, the total evaluation coefficient of order project 1 in regard to evaluation index 1 is

$$
n_{1}^{1}=n_{11}^{1}+n_{12}^{1}+n_{13}^{1}=5.475
$$

The grey evaluation weight vector of order project 1 associated with evaluation index 1 is

$$
r_{1}^{1}=\left(\begin{array}{lll}
0.7078 & 0.29220
\end{array}\right)
$$

The grey evaluation weight vectors of else order projects with respect to evaluation index 1 can be computed similarly.

$$
r_{2}^{1}=\left(\begin{array}{lll}
0.7078 & 0.2922 & 0
\end{array}\right), r_{3}^{1}=\left(\begin{array}{llll}
0.5649 & 0.4351 & 0
\end{array}\right), r_{4}^{1}=\left(\begin{array}{lll}
0.5932 & 0.4068 & 0
\end{array}\right), r_{5}^{1}=\left(\begin{array}{lll}
0.5102 & 0.4898 & 0
\end{array}\right)
$$

\subsection{Comprehensive evaluation}

Because

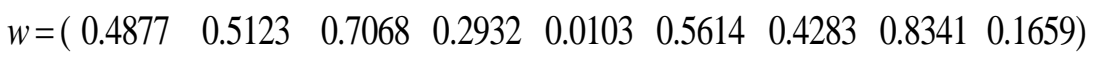

So the comprehensive score is

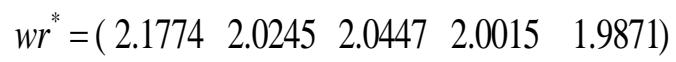

That is to say, the priority of order project is order project $1>$ order project $3>$ order project $2>$ order project $4>$ order project 5 .

\section{Conclusions}

In this paper, we have converted bulk order processing to priority evaluation of a variety of order project through the application of project management. In particular, we build the evaluation index system and multilevel grey comprehensive evaluation model strategically. About the solutions, the extension AHP method is reasonable. Finally, we have taken five orders as an example in detail. Although the evaluation model could sorted order project priority successfully, it only was the basis of reasonable allocation of resources in project management. Future studies also could be available from extra cost and customer satisfaction, making the uncertain models to solve each order item delivery time, the amount of resources and human resource allocation problem.

\section{References}

[1] B. Joseph Pine II, Mass Customization: The New Frontier in Business Competition, Boston: Harvard Business School, 1993.

[2] D. Bernhardt, Q.H. Liu and K. Serfes, Product customization, European Economic Review, 51(2006) 32-35.

[3] J. Wind and A. Rangaswamy, Customization: The next revolution in mass customization, Journal of Interactive Marketing, 15(2001) 13-32.

[4] C. Hart, Mass customization: Conceptual underpinnings, opportunities and limits, International Journal of Service Industry Management, 6(1995) 36-45.

[5] A. Kumar, Mass Customization: Metrics and Modularity, International Journal of Flexible Manufacturing Systems, 16(2005) 287-311.

[6] R. Duray, P. T. Ward, G. W. Milligan and W. L. Berry, Approaches to mass customization: configurations and empirical validation, Journal of Operations Management, 18(2000) 605-625.

[7] B.B. Li, L. J. He, C. X. Li and Y. Liu, Study on process capability indices (PCI) for mass customization, 2005 International Conference on Services Systems and Services Management, Proceedings of ICSSSM'05, 2005, pp.426-428.

[8] Sifeng Liu and Yi Lin, Grey Information: theory and practical applications, Springer London, 2006.

[9] D. F. Li, Multi-attribute decision making models and methods using intuitionistic fuzzy sets, Journal of Computer and System Sciences, 70 (2005) 73-85. 